\title{
Erratum to: Effects of proNGF on Neuronal Viability, Neurite Growth and Amyloid-beta Metabolism
}

\author{
Yan-Jiang Wang • Deborah Valadares · Ying Sun · Xin Wang • \\ Jin-Hua Zhong • Xiao-Hong Liu $\cdot$ Shohreh Majd $\cdot$ Li Chen $\cdot$ Chang-Yue Gao • \\ Si Chen · Yoon Lim • Anthony Pollard • Ernest A. Salegio • Wei-Ping Gai • \\ Miao Yang $\cdot$ Xin-Fu Zhou
}

Published online: 3 September 2011

(C) Springer Science+Business Media, LLC 2011

Erratum to: Neurotox Res (2010) 17:257-267

DOI 10.1007/s12640-009-9098-x

Author Ernest A. Salegio was incorrectly listed as "Ernest Aguilar" in the author list of the original article. Dr. Salegio's name appears correctly above and below.

The online version of the original article can be found under doi:10.1007/s12640-009-9098-x.

Y.-J. Wang · D. Valadares · Y. Sun · J.-H. Zhong - X.-H. Liu · S. Majd - L. Chen - C.-Y. Gao - S. Chen - Y. Lim - A. Pollard .

E. A. Salegio - W.-P. Gai · M. Yang · X.-F. Zhou ( $\bowtie)$

Department of Human Physiology and Centre for Neuroscience,

Flinders University, GPO Box 2100, Adelaide, SA, Australia

e-mail: xin-fu.zhou@ flinders.edu.au

X. Wang

Department of Biochemistry, Basic Research Institute,

Chinese Academy of Medical Sciences, Beijing, China 